\title{
Quem Autoriza o Aborto Seletivo no Brasil? Médicos, Promotores e Juízes em Cena ${ }^{1}$
}

\author{
DEBORA DINIZ
}

O Código Penal brasileiro não explicita o tema do aborto por anomalia fetal. Estima-se que já foram autorizadas duas mil interrupções da gestação por má-formação fetal incompatível com a vida no Brasil. Os anos 1990 foram decisivos para esse processo de reconhecimento do direito ao aborto seletivo, muito embora ainda exista intensa controvérsia jurídica em torno de sua legalidade. Este artigo analisa os argumentos utilizados por médicos, advogados, promotores e juízes para justificar a moralidade do primeiro pedido de aborto seletivo no Distrito Federal, em 1995.

Palavras-chave: Aborto seletivo; aborto por anomalia fetal; bioética feminista. 


\section{Introdução}

É expressão corrente entre obstetras e ginecologistas que "em um bom pré-natal a mulher realiza pelo menos uma ecografia". Em geral, a primeira ecografia é realizada no segundo trimestre da gestação. A ecografia, ao visualizar o feto, permite que especialistas em genética e em medicina fetal antecipem diagnósticos de má-formação fetal, que cirurgiões pediátricos planejem intervenções cirúrgicas intra-útero ou imediatamente após o nascimento, ou simplesmente tranqüiliza as mulheres quanto ao desenvolvimento da gestação, informando sobre sexo, tamanho e peso do feto. Se, por um lado, a ecografia ampliou as possibilidades de tratamento fetal, por outro, introduziu o tema do aborto por má-formação fetal no cenário do pré-natal ${ }^{3}$.

Grande parte das doenças e deficiências diagnosticadas pelas técnicas modernas de diagnóstico pré-natal não possui tratamento ou cura, o que faz com que, nos casos mais graves e limitantes, as mulheres desejem a interrupção seletiva da gestação. No Brasil, raríssimas são as mulheres grávidas que, diante de um diagnóstico de má-formação fetal incompatível com a vida, não buscam apoio médico e jurídico para interromper a gestação ${ }^{4}$. $\mathrm{O}$ diagnóstico da anencefalia, que será discutido neste artigo, é paradigmático para compreender as implicações éticas da ecografia em países onde o aborto é crime 5 .

Nos países onde essas técnicas foram originalmente desenvolvidas, havia um contexto político, legal e ético favorável à sua popularização: o aborto era legalmente permitido ou despenalizado. O reconhecimento público de que o aborto deveria ser uma questão de foro individual, quando muito familiar, vem sendo considerada pré-condição para a moralidade das modernas técnicas de diagnóstico fetal. O fato é que o diagnóstico de má-formação fetal, em especial daquelas incompatíveis com a vida extra-uterina, não compõe o rol de expectativas das mulheres grávidas. O diagnóstico da máformação fetal é, sem sombra de dúvida, uma das experiências mais angustiantes que uma mulher grávida pode experimentar. E parte importante dessa angústia decorre exatamente da precisão diagnóstica possibilitada pelas técnicas: há uma limitação técnica da medicina fetal, pois não há possibilidades terapêuticas para a grande maioria dos diagnósticos de má-formação fetal e, acrescido a isto, há uma limitação legal que restringe as decisões reprodutivas da mulher grávida, dificultando ou mesmo proibindo o aborto seletivo.

O aborto no Brasil é crime. Há excludentes de penalidade em casos de 
estupro (aborto sentimental) e risco à vida da mulher grávida (aborto terapêutico), existindo enorme resistência política a qualquer modificação da legislação por meio de projetos de lei no Congresso Nacional ${ }^{6}$. A intransigência moral que domina o debate no Brasil impede até mesmo propostas de modificação do Código Penal à luz de princípios constitucionais, como a liberdade ou a dignidade, um movimento que vem sendo gradativamente reconhecido como prioritário por alguns juízes, procuradores e promotores de justiça $^{7}$. Mas a participação crescente dos operadores do direito na questão do aborto é, por sua vez, uma conseqüência direta da difusão das técnicas de diagnóstico pré-natal, em especial da mais simples delas, a ecografia. A grande maioria dos processos judiciais e alvarás sobre o aborto no Brasil são casos de pedidos de autorização para a interrupção seletiva da gestação em casos de anomalias fetais incompatíveis com a vida ${ }^{8}$. Estima-se que mais de dois mil pedidos judiciais já foram feitos para autorizar interrupções seletivas da gestação no país, a grande maioria realizada em hospitais públicos ${ }^{9}$.

Reconhece-se o alvará de Rio Verde de Mato Grosso, no Mato Grosso do Sul, de 1991, com tendo sido o primeiro expedido no Brasil autorizando uma interrupção da gestação em caso de anencefalia ${ }^{10}$. No Distrito Federal, também foi um diagnóstico de anencefalia o que motivou o que se registra como o primeiro pedido de alvará, em 1995 (Brasil, 1995). Neste artigo, analisarei os argumentos utilizados por médicos, advogados, promotores e juízes para justificar a moralidade ou a imoralidade do aborto seletivo, tendo por estudo de caso o primeiro pedido de alvará do Distrito Federal.

\section{O Processo}

O primeiro processo do Distrito Federal seria um dentre os milhares existentes no Brasil, não fosse por três particularidades: 1) a extensão dos relatórios apresentados pelo advogado, pelo promotor e pelo juiz (setenta e uma páginas); 2) a negociação de competência para o julgamento entre o Ministério Público (promotor) e o Judiciário (juiz), o que enriqueceu a argumentação, e 3) o fato de ter sido negado o pedido de alvará, impedindo a interrupção da gestação. O processo teve início em 01 de dezembro de 1995, tendo sido intimado o advogado para conhecimento da sentença em 09 de fevereiro de 1996 e o processo arquivado em 26 de fevereiro do mesmo ano. Antes da data do arquivamento do processo, a mulher já havia parido o bebê, que falecera imediatamente após o nascimento. Entre o recebimento do diagnóstico e a sentença passaram-se quatro meses ${ }^{11}$.

Maria dos Santos era uma mulher de 27 anos, solteira e sem filhos, que 
tentou interromper a gestação por meio de misoprostol (Citotec) no segundo mês de gestação ${ }^{12}$. No processo não houve qualquer referência ao parceiro de Maria dos Santos e os documentos anexados ao processo desconsideraram sua existência. Sabe-se apenas que a gravidez foi resultado de um relacionamento não-estável. As primeiras linhas do processo assim resumiram sua história:

“(...) a requerente, em razão de relacionamento que vem mantendo com seu namorado, veio a engravidar. Gravidez essa não desejada, face ainda não terem um relacionamento estável. No entanto, apesar de não ter planejado essa gravidez, a Requerente começou imediatamente seu tratamento médico de pré-natal, temendo qualquer alteração de formação do feto em razão dos antecedentes familiares e dos antecedentes paternos (...). Em consulta médica de rotina, foi notado pelo médico que sempre acompanhou a Requerente suspeita de anormalidade na gestação (...). Ante o resultado dos exames, o médico da Requerente, para evitar qualquer providência precipitada, ou erro no diagnóstico, encaminhou-a para o Setor de Gestação de Alto Risco do [hospital] com diagnóstico de má-formação fetal (...)" (Brasil, 1995, p. 3).

Após ter tentado sem sucesso interromper a gestação, Maria dos Santos foi informada na terceira ecografia, com 21 semanas de gestação, que o feto apresentava má-formação ${ }^{13}$. Ao ser encaminhada a um serviço especializado, a quarta ecografia diagnosticou que o feto era anencefálico e que o prognóstico sugeria que "a grande maioria dos pacientes morre durante os três primeiros meses de vida. No entanto, alguns sobrevivem acima de 3 anos de idade, porém sem nenhuma função intelectual" (Brasil, 1995, p. 11).

O parágrafo de abertura do processo foi estrategicamente elaborado, resumindo algumas das variáveis centrais da argumentação em que tanto o advogado quanto o promotor sustentarão, respectivamente, a moralidade e a imoralidade da solicitação. Para o advogado, o ponto de partida para o julgamento deveria ser duplo: por um lado, a gravidez era não-planejada (muito embora não se mencione a tentativa de aborto no segundo mês de gestação) e, por outro, a relação afetiva de Maria dos Santos não era estável (um dado que o promotor irá, por sua vez, ironizar, grifando a expressão, sugerindo não compreender qual o conteúdo moral de um relacionamento).

É nesse quadro original de desamparo, segundo o advogado, que se deveria avaliar o impacto do diagnóstico de um feto anencefálico na vida de Maria dos Santos: uma mulher solteira, com uma gravidez não desejada e diante de um quadro limite de má-formação, porém impossibilitada legalmen- 
te de interromper a gestação sem antes recorrer à justiça. Com essa descrição de Maria dos Santos, o advogado, em uma clara tentativa de sugestionar o juiz e o promotor, sustentou que o pedido judicial justificavase por um mero formalismo, pois, dada a gravidade do caso, seria possível prescindir da avaliação judicial:

“(...) Na maioria dos casos, a parte interessada, juntamente com o médico, toma a decisão que considera apropriada e realiza a interrupção da gravidez sem que seja consultado o Poder Judiciário, a necessidade de autorização é devido a formalismos (...)" (Brasil, 1995, p. 4).

Infelizmente, a avaliação do promotor e do juiz não se resumiu a um mero formalismo, tendo sido decisiva para a vida de Maria dos Santos. O promotor foi implacável em seu despacho:

"O abortamento, ou os eufemismos que se queira utilizar, não é possível apenas com fulcro nos argumentos expendidos pela requerente, vez que não há evidências de que se enquadra dentre as hipóteses permissivas do artigo 128 do Código Penal" (Brasil, 1995, p. 57/58).

$\mathrm{O}$ argumento foi transformado em sentença pelo juiz, ao afirmar que "ante o exposto, indefiro o pedido de autorização judicial para interrupção da gravidez" (com grifo no original) (Brasil, 1995, p. 63). Ainda hoje, a despeito da jurisprudência acumulada no país, esta é uma peça decisiva para a realização de um aborto seletivo: sem a autorização do Ministério Público ou sem um alvará judicial, poucos médicos realizariam uma interrupção da gestação de fetos inviáveis em um hospital público.

$\mathrm{O}$ aspecto trágico da gestação de Maria dos Santos não se resumiu ao fato de a gravidez não ter sido planejada ou de a tentativa de interrompêla não ter sido bem-sucedida, mas especialmente pela gravidade do diagnóstico e pela intransigência do promotor em acatar a solicitação de interrupção ${ }^{14}$. O processo do advogado de Maria dos Santos é impecável, desde a composição da história até a apresentação dos documentos médicos, em especial pela seqüência das imagens ecográficas, sendo a argumentação de seu advogado uma das mais cuidadosas da jurisprudência nacional no tema. Assim como a grande maioria dos processos brasileiros, o advogado de Maria dos Santos evitou qualificar a solicitação de interrupção da gestação como aborto (um dado registrado pelo promotor como "eufemismos"), fundamentando a excepcionalidade do processo em três argumentos, nesta ordem de importância: 1) a precisão científica que demonstrava a inviabilidade fetal 
de um feto anencefálico; 2) a saúde mental de Maria dos Santos, e 3) o prolongamento da gestação deveria ser entendido como um ato de tortura. Os dois primeiros argumentos são, tradicionalmente, utilizados nos processos brasileiros, tanto por advogados, promotores quanto juízes, sendo o último argumento raramente discutido no Brasil ${ }^{15}$.

\section{Os Três Argumentos do Advogado}

Para um processo de autorização de aborto seletivo ter alguma chance de ser deferido, é preciso que o laudo médico seja inquestionável. E mais do que isso: deve ser impossível duvidar da sentença de inviabilidade fetal. É preciso que o laudo médico que sustenta a gravidade e inviabilidade fetal seja parte do senso comum da comunidade médica. O advogado de Maria dos Santos sabia disso e não hesitou em sustentar seus primeiros argumentos no parecer médico, que dizia:

"O diagnóstico (...) foi proferido com exação tecnológica, precisão científica, baseado em exame moderno, e não em mera predisposição hereditária (...) ou em hipótese e conjecturas, sem nenhuma base científica (...)" (Brasil, 1994, p. 3).

O argumento partiu da suspeita da má-formação na terceira ecografia para a "exação tecnológica e precisão científica" do diagnóstico de anencefalia na última ecografia. Para o advogado, não havia dúvidas de que o feto de Maria dos Santos estava fadado à morte prematura, fato indiscutivelmente descrito pela medicina.

Mas a habilidade do advogado, ao utilizar os argumentos científicos que comprovavam a inviabilidade do feto, não se resumiu a amparar seus argumentos nos laudos e imagens ecográficas. Após descrever os fundamentos da certeza diagnóstica, o advogado iniciou uma nova seção no processo, intitulada "Das Razões do Pedido", onde redescreveu o vocabulário biomédico em termos sociomorais, sendo este um dos pontos altos do documento:

“(...) Sob o ponto de vista científico, conceptos hidranencefálicos seguramente não têm condições de sobrevida, sucumbindo logo após sua expulsão, ou podendo sobreviver até 3 anos, mas sem qualquer função intelectual. Na linguagem pobre, se ultrapassado os primeiros momentos de vida extrauterina, 'vegetará' por pouco tempo até sucumbir (...)" (Brasil, 1994, p. 4).

Feto, vida, nascimento e morte, conceitos corriqueiros, tornaram-se 
"concepto, sobrevida, expulsão e morte". Esse não foi um mero exercício lingüístico de apaziguamento moral, mas sim uma tentativa de, ao substituir os termos descritivos, distanciar o processo dos pressupostos tradicionais do debate sobre a moralidade do aborto. Segundo o advogado, não havia feto, vida, nascimento ou morte, mas algo que, após expulso, se assemelharia a um vegetal. A desumanização do feto, uma estratégia comum aos processos judiciais de aborto seletivo no Brasil, foi apenas metaforicamente sugerida pelo advogado de Maria dos Santos ${ }^{16}$. Além disso, a supremacia da função intelectual para qualificar o humano foi um argumento sobreposto a todos os outros, prevendo qualquer tentativa de contra-argumento que buscasse questionar o que qualificaria a vida humana. Mas, como veremos adiante, esse também foi um argumento revisto pelo promotor.

Ao substituir feto por concepto, vida por sobrevida, nascimento por expulsão e morte por sucumbência, o advogado evitou o nó argumentativo do debate sobre a moralidade do aborto no Brasil: fundamenta-se a imoralidade da interrupção da gestação no pressuposto de que o feto, por estar vivo, seria pessoa e, ao ser pessoa no sentido jurídico do termo, possuiria expectativas de direitos. Feto e pessoa são conceitos tradicionalmente intercambiáveis pelos que suportam a imoralidade do aborto, assim como vida e potencialidade de vida extra-uterina (Wertheimer, 1974; Finnis, 1973; Boonin, 2003). Ao sustentar que o feto de Maria dos Santos não poderia ser descrito nos termos tradicionais do aborto, o advogado abriu o único caminho moralmente possível para a negociação da moralidade do aborto seletivo no Brasil: mostrar que a inviabilidade fetal impossibilitava a transposição dos conceitos. $\mathrm{O}$ aborto seletivo não poderia ser legal e moralmente negociado nos mesmos termos do aborto voluntário, por isso o advogado ignorou estratégias baseadas nos direitos ou na liberdade reprodutiva de Maria dos Santos. Após a breve exposição da situação de desamparo afetivo de Maria dos Santos, o objeto de negociação do processo passou a ser a gravidade da máformação fetal. E, nesse sentido, todos os esforços argumentativos do advogado concentraram-se em demonstrar o quanto o diagnóstico de anencefalia transformava Maria dos Santos em uma vítima do azar.

Não apenas o advogado procurou diferenciar o processo de Maria dos Santos das situações tradicionais de aborto voluntário, como fez menção explícita a essa diferença, por meio de uma citação de outro jurista: “(...) não se pretende defender a interrupção da gravidez decorrente da só vontade da Mãe, independentemente das condições do feto (...)" (Brasil, 1995, p. 6). A má-qualidade do feto era, portanto, a razão do processo. Se não 
houvesse um feto inviável, não haveria processo, segundo o advogado. Após a tentativa malsucedida de aborto e antes do diagnóstico da anencefalia, Maria dos Santos era uma mulher conformada com a gestação, muita embora descrita como psicologicamente abalada. Para evitar mal-entendidos desnecessários ao processo, o advogado não discordou da interpretação jurídica vigente no Brasil de que a vida humana em qualquer estágio de desenvolvimento deveria ser considerada um bem inalienável, por isso qualquer forma de prática de aborto deveria ser interpretada como um atentado ao direito absoluto e fundamental à vida. E, como veremos na exposição do juiz, foi esse acordo forçado com a lei o que determinou o indeferimento da sentença. O processo não era, na perspectiva do advogado e do juiz, o momento de negociar a legislação do aborto no Brasil, a tal ponto que o juiz, em tom de desabafo, registrou:

“(...) não se pode mais submeter aquelas mulheres que admitem o aborto na clandestinidade, à vergonha e à sanha de 'mercenários'. Ocorre que o julgador deve obediência à Constituição da República e às Leis. Tenho que o nosso ordenamento jurídico vigente não contempla a hipótese de aborto eugenésico (...)” (Brasil, 1995, p. 62).

$\mathrm{Na}$ verdade, o juiz não apenas cedeu à interpretação jurídica hegemônica no Brasil, mas principalmente ao despacho do promotor, que considerou ilegal a solicitação.

O segundo argumento do advogado, o de que a manutenção da gestação provoca riscos físicos e psíquicos à mulher, é o mais comum na jurisprudência de aborto seletivo no Brasil. Nessa linha argumentativa, o aborto seletivo deveria ser incluído no excludente de penalidade do aborto terapêutico, ou, nas palavras do advogado:

\footnotetext{
“(...) tomando conhecimento da referida situação, a Requerente passou a ficar perturbada psicologicamente, ante a confirmação de não ter um filho em condições de sobrevida, trazendo sérios riscos a sua vida, e ainda desorganização familiar. Do ponto de vista psiquiátrico, a Requerente encontra-se deprimida (...)" (Brasil, 1995, p. 4).
}

Se, por um lado, esse argumento é o de mais fácil negociação jurídica, pois pressupõe uma brecha judicial já existente, por outro é o de maior contestação na parceria dos médicos com os promotores e juízes ${ }^{17}$. Há casos de anomalias fetais que, indiscutivelmente, provocam sérios riscos à saúde da mulher; e outros em que intencionalmente se reforça o risco 
mínimo considerado como "natural" a qualquer gestação. Esse ajustamento da força do laudo médico para justificar a justaposição do aborto terapêutico e do aborto seletivo vem sendo alvo de inúmeras controvérsias e foi um dos pontos-chave da resistência do promotor em acatar o argumento do advogado de Maria dos Santos. O promotor optou por entender risco à saúde no sentido estrito do princípio: risco à saúde deveria ser risco à vida de Maria dos Santos e não apenas os riscos comuns de uma gestação ou os transtornos psíquicos causados pelo diagnóstico.

$\mathrm{Na}$ verdade, Maria dos Santos não foi apenas uma vítima do azar, mas com a imposição da continuidade da gravidez, era vítima de seu feto. A sobreposição da ilegalidade do aborto ao azar levou o advogado a argumentar a moralidade do aborto seletivo no artigo $5^{\circ}$ da Constituição Federal, que sustenta que ninguém será submetido a tortura nem a tratamento desumano ou degradante. Dado que Maria dos Santos não desejava a manutenção da gravidez, a obrigatoriedade de manter-se grávida de um feto anencefálico, ou seja, de um feto fadado à morte imediatamente após o nascimento, deveria ser entendida como um ato de tratamento torturante. $\mathrm{O}$ argumento da tortura é o de encerramento do processo e introduz um novo argumento ao debate sobre aborto seletivo no Brasil: o de entendê-lo como um caso de violação de direitos humanos ${ }^{18}$. Este foi um trecho do processo em que o advogado assumiu um tom mais impositivo, afirmando que "(...) a continuação da gravidez, como relata o Laudo da Comissão de Ética Médica, é totalmente desnecessária e irresponsável (...)” (Brasil, 1995, p. 6).

Ao introduzir o argumento da manutenção da gravidez como um tratamento torturante, desnecessário e irresponsável, o advogado teve o cuidado de espantar o fantasma que persegue o debate sobre aborto seletivo no Brasil: o da eugenia. Assim como a grande maioria dos processos brasileiros, o advogado de Maria dos Santos assentou sua solicitação na certeza da inviabilidade da vida extra-uterina do feto, afirmando, por meio de uma citação, que "(...) não se pretende, insisto, que quaisquer anomalias ou deformidades dêem ensejo à interrupção da gravidez (...)" (Brasil, 1995, p. 6). $\mathrm{O}$ que o processo buscava regulamentar era, tão somente, o reconhecimento da certeza da inviabilidade fetal, diferentemente do que foi proposto pelo promotor, por exemplo, que traçou paralelos entre o pedido de Maria dos Santos com o extermínio de pessoas pobres ou deficientes, sugerindo uma semelhança entre fetos anencefálicos, pessoas pobres e deficientes: todas seriam, na opinião do promotor, socialmente indesejáveis e, portanto, passíveis de serem exterminadas, caso se diminuísse a vigilância moral sobre atos 
ilícitos como o solicitado por Maria dos Santos. Esse argumento do risco moral é recorrentemente discutido nos processos de aborto seletivo no Brasil, sendo conhecido por "ladeira escorregadia", ou seja, a autorização de um novo permissivo legal para o aborto provocaria uma extensão das prerrogativas morais das pessoas frente à reprodução, conduzindo a uma maior tolerância frente a práticas como infanticídio ou eutanásia neonatal. $\mathrm{Na}$ verdade, foi o promotor quem explicitou o risco da eugenia e da ladeira escorregadia no processo, classificando a interrupção da gestação de um feto anencefálico como "aborto eugenésico".

Certamente a fronteira do aborto seletivo com valores eugênicos não é fácil de ser estabelecida. Este é um dos debates mais acirrados no campo da bioética feminista, sendo Adrienne Asch uma das precursoras da crítica expressivista ao aborto seletivo nos anos 1990 (Asch, 1999; Parens e Asch, 1999). Asch é uma filósofa e pesquisadora feminista da bioética que defende o seguinte argumento: o aborto voluntário deve ser moralmente neutro, isto é, não há qualquer problema nas mulheres optarem por interromper uma gestação, mas o aborto seletivo necessita ser avaliado à luz dos interesses e direitos das pessoas deficientes. Segundo Asch, diferentemente de outras situações de aborto voluntário, o aborto seletivo ocorre após a mulher ter desejado a gestação. É uma gestação desejada, ou, no caso de Maria dos Santos, uma gestação não-planejada que se torna, após o diagnóstico da máformação fetal, indesejada. O fato de o diagnóstico de má-formação ser mais seguro em uma fase da gestação já mais avançada, em geral em torno da décima oitava semana, é um dos pontos que reforça o argumento de Asch de que a gravidez já fazia parte do projeto pessoal e social da mulher. É o diagnóstico da má-formação que faz com que a mulher repudie a gestação, uma correlação que Asch considera perigosa para os deficientes, caso não seja amplamente discutida. Em nome dessa relação que as mulheres estabeleceriam com os fetos com má-formação, Asch sugere que o aborto seletivo seria moralmente problemático, pois, ao interromper a gestação, as mulheres estariam fundamentando sua decisão em uma imagem negativa dos deficientes, tanto quanto estariam enviando uma "mensagem negativa" aos deficientes, por isso o argumento foi adjetivado de expressivista. A crítica expressivista sugere que a popularização do aborto seletivo pode provocar conseqüências perversas para os deficientes, caso o debate não seja acompanhado de um fortalecimento dos direitos sociais dos deficientes.

Asch não discute diretamente a eugenia, mas ampara a crítica expressivista em pressupostos semelhantes aos das feministas que resistem à moralidade 
da seleção de sexo, traçando um paralelo entre os pressupostos de inferioridade dos deficientes à opressão de gênero. Assim como teríamos ideologias sexistas e racistas, a autora, na esteira dos estudos anglo-saxões do movimento social da deficiência, supõe que há uma ideologia que pressupõe a inferioridade dos deficientes ${ }^{19}$. A crítica expressivista ao aborto seletivo foi duramente criticada por feministas, antropólogos, filósofos e outros pesquisadores da bioética ${ }^{20}$. Não apenas o pressuposto da intencionalidade da mensagem foi discutido, como também a idéia de que cresceria a intolerância aos deficientes ao se permitir o aborto seletivo. Estudos etnográficos sobre as escolhas reprodutivas das mulheres após diagnóstico genético prénatal mostraram que não havia a correlação ideológica sugerida por Asch (Raap, 1999). Muito embora a crítica expressivista seja alvo de intensas discussões no cenário estadunidense, onde o aborto voluntário é legalmente permitido até a vigésima quarta semana de gestação e, em casos de máformação, em estágios mais avançados é importante lembrar qual a idéia de deficiência discutida pela crítica expressivista.

Não há como transpor os fundamentos da crítica expressivista de Asch para a realidade brasileira. A idéia de deficiência que Asch tem em mente é a idealizada pelo movimento Surdo e não o feto anencefálico de Maria dos Santos. Asch e as teóricas da crítica expressivista não discutem quadros clínicos de má-formação incompatível com a vida, pois nesses casos não há outra saída senão reconhecer a soberania da vontade da mulher grávida em interromper ou não a gestação. Não há ajustes no sistema cooperativo vigente, não há priorização na alocação de recursos para a incorporação das necessidades da criança deficiente ou mesmo altruísmo materno que modifiquem a sentença da inviabilidade fetal, o que torna, como veremos, o receio eugênico do promotor antes uma estratégia discursiva para fundamentar suas crenças religiosas particulares que mesmo uma discussão cuidadosa das implicações do aborto seletivo no Brasil.

\section{Os Três Argumentos do Promotor}

O processo foi, inicialmente, encaminhado para o juiz, mas o promotor reclamou ser o caso de competência do Ministério Público. O juiz declinou sua competência, muito embora, após a avaliação do promotor, o processo tenha retornado às suas mãos para a sentença. A declinação de competência foi resultado de um acordo de boa vizinhança entre o Judiciário e o Ministério Público, que será determinante para a sentença de indeferimento. 
Há uma extensa discussão no país sobre a quem cabe o julgamento do mérito dos pedidos de aborto seletivo, havendo tanto alvarás de juízes quanto despachos de promotores. No Distrito Federal, desde 1999, após a implantação de uma promotoria especializada em casos de aborto seletivo, todos os processos são decididos pelo Ministério Público, não acontecendo o mesmo em outros locais do país.

Assim como o advogado, o promotor concentrou seus argumentos em três pontos: 1) crítica ao conceito de normalidade vigente; 2) risco do relativismo moral, e 3) ilegalidade da solicitação. O último argumento, uma interpretação literal da legislação vigente sobre aborto, não estabelece uma relação de dependência com os dois primeiros argumentos, ou seja, a extensa crítica à idéia de normalidade e os riscos do relativismo moral não são argumentos necessários para o indeferimento do processo. $\mathrm{O}$ promotor não necessitava das onze páginas de argumentação para concluir que o artigo 128 do Código Penal não contempla o aborto seletivo. Mas é intrigante analisar as múltiplas variáveis discutidas pelo promotor no decorrer do despacho, especialmente pela tentativa de diálogo moral que imaginou travar com os argumentos expostos pelo advogado de Maria dos Santos.

O promotor ignorou por completo o fato de a anencefalia ser uma anomalia incompatível com a vida e construiu sua argumentação na suposição de que o conceito de inviabilidade era uma construção moral pautada no repúdio aos deficientes ou, em seus próprios termos, nas pessoas sem aptidão para vencer:

“(...) a competitividade faz crer que somente aqueles que possuem aptidão para 'vencer' na vida são viáveis. Existe, subliminarmente, nas consciências, uma diferenciação: ou se é um vencedor ou um perdedor. Se é um perdedor, deve ser relegado a um segundo plano (...)” (Brasil, 1995, p. 49).

Em seguida, sustentou que essa era uma lógica egoísta defendida inclusive por aqueles que "se apresentam como árduos defensores do que chama direitos humanos" - clara ironia ao argumento do advogado de Maria dos Santos (Brasil, 1995, p. 49). Nesse esquecimento intencional das implicações do diagnóstico, o promotor tomou para si a missão de proteger a humanidade do risco moral da ladeira escorregadia, caso autorizasse Maria dos Santos a fazer o "aborto eugenésico".

A missão heróica do promotor sustentou-se na crítica à idéia de normalidade que ele alegava estar implícita no pedido do advogado e na ameaça que a defesa do relativismo moral é para a humanidade. Curiosamente, 
nenhum dos dois argumentos foi discutido pelo advogado de Maria dos Santos, sendo esses pontos importantes para os valores religiosos do promotor, ao que tudo indica um católico, haja vista que um quarto do despacho foi preenchido por trechos sobre o aborto do Evangelium Vitae, de autoria do Papa João Paulo II. Antes de citar os principais dogmas de João Paulo II em sua crítica às idéias de autonomia individual da cultura democrática, o promotor sentenciou que:

“(...) vive-se em uma sociedade em que se pugna pela relativização dos valores. Nenhum valor é absoluto. Nem amor, lealdade ou mesmo a vida é um valor absoluto. Não, assim não pode ser. Existem alguns valores que não podem jamais ser abandonados (...)" (Brasil, 1995, p. 52).

$\mathrm{O}$ valor que não poderia ser negociado, segundo o promotor, era o do direito à vida do nascituro, indiferente "às anomalias e deformidades que apresente" (Brasil, 1995, p. 52). O promotor esqueceu-se, todavia, que para imputar o princípio do direito à vida ao feto era preciso haver potencialidade de viver a vida, algo inexistente no caso de um feto anencefálico (Diniz, 2003a).

Mas o esquecimento do promotor não se resumiu a ignorar o que caracteriza a anencefalia. Apoiado no laudo médico que mencionava a rara chance de três anos de sobrevida, o promotor sugeriu que:

"por que então negar a este ser que está por nascer um pouco de carinho pelos poucos dias em que desfrutará do convívio entre os mortais? Um dia ele amanhecerá frio, sem vida, mas a mãe terá para si, desde o primeiro dia, a convicção de que cumpriu o seu papel, que deu carinho àquele que por aqui passou, mesmo que só de passagem" (Brasil, 1995, p. 53).

Neste momento, Maria dos Santos assumiu o papel de mãe no processo, nem que fosse para acalentar uma criança morta. O risco moral da ladeira escorregadia provocou pânico no promotor, que se sentiu à vontade para descrever um quadro fantástico de opressão e extermínio dos fracos, caso autorizasse o aborto de Maria dos Santos:

“(...) ceder, ainda que em casos isolados, é abrir um perigoso precedente àqueles que, munidos de conceitos apriorísticos do que seja normal, pretendem 'melhorar o padrão biológico do homem, criar uma geração sadia, forte e bela'. De repente, o negro não se encaixa dentro desse padrão de normalidade, o baixinho, o velho, a criança menos inteligente (...)" (Brasil, 1995, p. 53 - sem grifos no original). 
Fetos anencefálicos, pessoas negras, baixinhas, idosas e crianças com dificuldades de aprendizagem foram ameaçados pelo pedido de Maria dos Santos. O espanto moral do promotor ao julgar um pedido de aborto foi tão intenso que ele agregou pessoas e situações de vida díspares: não há termos morais de comparação entre a discriminação social sofrida por negros e idosos à incapacidade de sobrevida de um feto anencefálico, sendo até mesmo um desrespeito ao sofrimento de Maria dos Santos comparar sua situação ao descrédito estético dos baixinhos. Uma análise cuidadosa das expressões discursivas do promotor mostra o quanto seu julgamento foi antes fundado no terror que na reflexão: ceder era o verbo que resumiria sua ação, caso concordasse com o pedido de aborto seletivo, e de repente foi a expressão de sua incapacidade de controlar o espanto moral frente uma situação tão indesejável quanto autorizar um aborto seletivo.

A maior ousadia argumentativa do promotor, no entanto, foi traçar suposições sobre um drama de consciência de Maria dos Santos. Após extensa digressão sobre os riscos e perigos de se ceder frente a casos como o que analisava, o promotor, em um claro movimento autojustificativo de suas premissas morais, interpretou o pedido judicial de autorização do aborto seletivo como um indício de que Maria dos Santos não estava segura de sua decisão: “(...) a requerente diante do caso concreto viu-se em conflito consigo mesma, com seus valores. Por isso não fez o aborto clandestinamente. Tem para si a consciência que poderia fazer mais, por si e pelo nascituro (...)” (Brasil, 1995, p. 55). O pedido judicial tornou-se não um sinal da submissão de Maria dos Santos à lei que proíbe o aborto, mas a peça que faltava ao promotor para convencer-se de que ela, na verdade, não desejava interromper a gestação. Maria dos Santos era uma mulher vítima da cultura eugênica ("cultura da morte") que a forçava solicitar a autorização. A conclusão do promotor foi de que o pedido judicial indicava o quanto Maria dos Santos não desejava o aborto. O sentido do proibido para o promotor não era o da ilegalidade do aborto, e por isso o pedido judicial de alvará, mas sim o próprio desejo de Maria dos Santos por interromper a gestação. Antes de finalizar o despacho mencionando o artigo 128 do Código e, portanto, indeferindo o pedido de alvará, o promotor confortou-se com a fantasia de ter descortinado a verdadeira razão do processo de Maria dos Santos: ela era "vítima dos contravalores divulgados e tão pouco combatidos" (Brasil, 1995, p. 57). De algoz do desejo de Maria dos Santos, o promotor converteu-se em seu salvador, naquele que a protegia da "cultura da morte" (Brasil, 1995, p. 57). 


\section{A Angústia e a Obediência do Juiz}

O juiz recebeu o despacho do promotor e iniciou a sentença com uma assertiva que resumiu sua participação no caso: "a questão em apreciação é de extrema complexidade (...) contudo, está muito longe o tempo em que o consenso prevalecerá (...)” (Brasil, 1995, p. 61). O juiz registrou o argumento corrente daqueles que defendem uma revisão da legislação sobre aborto no país, defendendo "a inegável transformação do mundo nos últimos cinqüenta anos (...) a matéria está merecendo um debate amplo, sem preconceitos, uma adequação aos tempos atuais (...)" (Brasil, 1995, p. 61), mas não foi capaz de enfrentar a fantasia eugênica delineada pelo promotor, tampouco reconheceu legitimidade nos argumentos do advogado, tendo, em linhas gerais, os ignorado. A sentença foi breve, quatro páginas, e afora as digressões iniciais sobre o anacronismo da legislação brasileira sobre aborto, foi meramente um atestado de concordância com o despacho do promotor. Havia forte sentimento de angústia na sentença do juiz, mas o argumento da obediência à lei resolveu-lhe dois problemas: o primeiro de não ter que enfrentar as sutilezas argumentativas do aborto seletivo no Brasil, e o segundo, de não se indispor com o promotor, que foi contrário ao deferimento do pedido.

\section{Observações Finais}

A história de Maria dos Santos é única e trivial ao mesmo tempo. Única por resumir em torno de si uma seqüência de fatos indesejados: a gravidez não-planejada, o insucesso da tentativa de aborto no segundo mês de gestação, o diagnóstico de má-formação, o indeferimento do processo e a morte da filha. Mas é também trivial por ser o enredo de muitas outras mulheres torturadas pelo azar de uma gravidez de feto inviável, em uma legislação que não apenas as obriga a expor publicamente seu sofrimento, mas a ter que negociar suas preferências, mesmo que em condições absolutamente desiguais de diálogo moral. Maria dos Santos foi esquecida em todas as fases desse processo. Seu advogado, provavelmente como parte de uma estratégia jurídica, a resumiu a um sujeito psiquicamente sofredor. O sujeito do processo foi seu feto. Não havia outra saída para a negociação, o que apenas demonstra a impossibilidade de qualquer diálogo racional em torno do aborto no Brasil.

Se, por um lado, o juiz angustiou-se diante do caso, ele também temia a 
fúria do promotor, um ardente opositor do aborto. Maria dos Santos provocava fantasias eugênicas no promotor, que temia ceder às seduções do mundo imaginário do risco moral. $\mathrm{O}$ mundo imoral que ameaçou a tranqüilidade dos absolutos inegociáveis do promotor é onde esteve Maria dos Santos durante nove meses e, quem sabe, ainda hoje permanece.

Mais do que qualquer outra situação de aborto, o diagnóstico de máformação fetal incompatível com a vida submete as mulheres à opressão implacável de que todos devemos acreditar na mesma interpretação do sentido da vida humana que a proposta pelo promotor que indeferiu seu processo. Maria dos Santos teve que acatar os argumentos eticamente infundados e assentados em um código religioso específico, travestidos da autoridade legal do Ministério Público. O despacho do promotor, um conjunto de fantasias eugênicas sobre a possibilidade de interrupção da gestação de um feto anencefálico, decidiu os rumos da vida de Maria dos Santos: não apenas determinou-se que seria mais prazeroso acalentar um bebê frio pela morte, que abortá-lo precocemente, quanto se teve a arrogância de qualificar o extremo sofrimento de Maria dos Santos como um conjunto de sentimentos "comodistas, egoístas e eugênicos".

O pedido de alvará para aborto seletivo de Maria dos Santos foi negado. Mas não foi apenas a vida dessa mulher que foi ameaçada pelos devaneios autoritários do promotor. E é nesse exato momento que a história de Maria dos Santos se torna trivial. O tema do aborto não é uma questão isolada de mulheres que, caprichosamente, decidem não ter filhos. É preciso modificar os termos descritivos com que se discute aborto no Brasil. O aborto é uma questão de extremo sofrimento e o aborto seletivo uma decisão de incalculável angústia para as mulheres grávidas. Por isso, não é possível que solicitações tão íntimas e angustiantes, como um pedido de alvará para interromper uma gestação de feto inviável, sejam arrogante e irresponsavelmente argumentadas como foi a de Maria dos Santos. E o pior: que o resultado seja a imposição de uma sentença cruel. 


\section{Referências Bibliográficas}

ALTEMEYER, F. A única exceção. Jornal do Brasil. 01/04/1996.

ALTEMEYER, F. Um luto anunciado. Jornal do Brasil. 1996.

$\mathrm{ASCH}, \mathrm{A}$. Prenatal diagnosis and selective abortion: a challenge to practice and policy. American Journal of Public Health, v. 89, n. 11, p. 1.649-57, 1999.

$\mathrm{ASCH}, \mathrm{A}$. Why I haven't changed my mind about prenatal diagnosis: reflections and refinements. In: PARENS, E.; ASCH, A. Prenatal testing and disability rights. Washington: Georgetown, 2000. p. 234-259.

BALTAR, M. I. A questão do aborto no Brasil: o debate no Congresso. Estudos Feministas, n. 2, p. 381-398, 1996.

BOONIN, D. A defense of abortion. Cambridge: Cambridge University Press, 2003.

BRASIL. Ministério Público do Distrito Federal e Territórios. Processo. 10/ 11/2002, p. 3.

BRASIL. Poder Judiciário. Sentença. 07/07/1994, p. 15.

BRASIL. Vara do Tribunal do Júri e dos Delitos de Trânsito da Circunscrição Judiciária do Gama. Sentença. 19/12/1995.

BUGLIONE, S. Comunicação [mensagem pessoal]. Mensagem obtida por $\leq$ d.diniz@anis.org.br>em 10 jul. 2003.

CONSELHO FEDERAL DE MEDICINA. Parecer. Relator: Conselheiro Sérgio Ibiapina Ferreira Costa. Relator de Vista: Conselheiro Marco Antônio Becker. N. 24/2003. 9/05/2003.

COSTA, D. Promotoria de Justiça Criminal de defesa dos usuários do serviço de saúde - Pró-Vida. Revista do Ministério Público do Estado de Pernambuco. Recife, v. 3, n. 1. p. 239-244, 2000.

DINIZ, D.; RIBEIRO, D. C. (Ed.). Aborto por anomalia fetal. Brasília: Letras Livres, 2003.

DINIZ, D. Antecipação terapêutica de parto: uma releitura bioética do aborto por anomalia fetal no Brasil. In: DINIZ, D.; RIBEIRO, D. C. (Ed.). Aborto por anomalia fetal. Brasília: Letras Livres, 2003a.

Modelo social da deficiência: crítica feminista. Brasília: LetrasLivres, 2003b. (Série Anis, n. 28). $1,1997$. O aborto seletivo no Brasil e os alvarás judiciais. Bioética, v. 5, n.

Um espelho das moralidades: o debate sobre aborto no Congresso Nacional Brasileiro. Perspectivas em saúde e direitos reprodutivos. São 
Paulo, n. 5, ano 3, p. 24-27, maio 2002. Disponível em: <www.camara.gov.br>. . Interrupção seletiva da gestação: aspectos éticos. Brasília, 2003c. Mimeografado.

FINE, M.; ASCH, A. Women with disabilities: essays in psychology, culture, and politics. Philadelphia: Temple University Press, 1988.

FINNIS, J. The rights and wrongs of abortion: a reply to Judith Thomas. Philosophy \& Public Affairs, v. 2, n. 2, p. 117-45, Winter, 1973.

FRANCIS, L. P.; SILVERS, A. American with disabilities: exploring implications of the law for individuals and institutions. New York: Routledge, 2000.

GOLLOP, T. Interrupção seletiva da gestação: aspectos sanitários. Palestra proferida por ocasião da Audiência Pública sobre Interrupção Seletiva da Gestação. Porto Alegre: Ministério Público Federal, abril 2003.

GUILAM, C. O discurso do risco na prática do aconselhamento genético pré-natal. Tese (Doutorado em Saúde Coletiva) - Instituto de Medicina Social, Universidade do Estado do Rio de Janeiro, 2003.

KITTAY, E. F. On the expressivity and ethics of selective abortion for disability: conversations with my son. In: PARENS, E.; ASCH, A. (Ed.). Prenatal testing and disability rights. Washington: Georgetown, 2000, p. 165-196.

NELSON, J. L. The meaning of the Act: reflections on the expressive force of reproductive decision making and policies. In: PARENS, E.; ASCH, A. (Ed.). Prenatal testing and disability rights. Washington: Georgetown, 2000, p. 196- 213.

OLIVER, M. The politics of disablement: critical texts in social work and the Welfare State. London: Macmillan, 1990.

OlIVER, M.; BARNES, C. Disabled People and Social Policy: from exclusion to inclusion. New York: Longman, 1998.

PARENS, E.; ASCH, A. The disability rights critique of prenatal genetic testing. Hastings Center Report. v. 29, n. 5, p. S1-S22, Sep/Oct. 1999.

PRESS, N. Assessing the expressive character of prenatal testing: the choices made or the choices made available. In: PARENS, E.; ASCH, A. (Ed.). Prenatal testing and disability rights. Washington: Georgetown, 2000, p. 214-233.

RAAP, R. Testing women, testing the fetus: the social impact of amniocentesis in America. New York: Routledge, 1999.

RIO VERDE DE MATO GROSSO. Juízo de Direito da Comarca de Rio Verde de Mato Grosso. Sentença. Autos n. 079/91, emitidos em 19/05/1991. 
TAHAN, L. Ela desafiou a ciência. Correio Braziliense. Brasília, 14/02/ 2003.

TESSARO, A. Aborto seletivo: descriminalização e avanços tecnológicos da medicina contemporânea. Curitiba: Juruá, 2002. p. 99-106.

THOMAS, C. Female forms: experiencing and understanding disability. Buckingham: Open University Press, 1999.

WENDELL, S. The rejected body: feminist philosophical reflections on disability. New York: Routledge, 1996.

WERTHEIMER, R. Understanding the abortion argument. In: COHEN, M.; NAGEL, T.; SCANLON, T. (Ed.). The rights and wrongs of abortion. Princeton: Princeton University Press, 1974, p. 23-51.

WERTZ, D.; FLETCHER, J. Feminist criticism of prenatal diagnosis: a response. Clinical Obstetrics and Gynecology, v. 36, n. 3, p. 541-67, 1993. WERTZ, D.; FLETCHER, J. Sex selection through prenatal diagnosis. In: HOLMES, B.; PURDY, L. Feminist perspectives in medical ethics. Bloomington: Indiana University Press, 1992. p. 240-253.

\section{NOTAS}

1 Agradeço à Promotoria de Justiça Criminal de Defesa dos Usuários do Serviço de Saúde, do Ministério Público do Distrito Federal e Territórios, pela parceria para pesquisa e intervenção sobre o aborto seletivo, e à equipe de medicina fetal de alto risco do Hospital Regional da Asa Sul, onde desenvolvo o trabalho de campo. Para evitar qualquer constrangimento e garantir o anonimato dos personagens envolvidos nos processos judiciais analisados, não fiz referências nominais aos operadores do direito (advogado, promotor e juiz) e aos médicos, além de ter excluído qualquer referência na bibliografia. Para as mulheres foram utilizados pseudônimos. Alguns dos argumentos presentes neste artigo foram mais extensamente discutidos em Diniz e Ribeiro (2003).

2 Doutora am Antropologia. Diretora da ANIS: Instituto de Bioética, Direitos Humanos e Gênero.

3 Além da má-formação fetal, outro tema que vem provocando intensas discussões é o uso da ecografia para a seleção do sexo do futuro bebê. Países como Índia ou China, onde há preferência cultural por meninos, a ecografia é estritamente controlada, havendo, inclusive, regiões onde é proibida. O aborto por seleção de sexo é um dos temas que mais intensamente provocou debate em bioética feminista nos anos 1990, havendo posicionamentos inconciliáveis: de um lado, defende-se que a autonomia reprodutiva da mulher deva ser soberana a qualquer constrangimento; por outro, argumenta-se que a seleção negativa de meninas espelha a opressão de gênero vigente nessas culturas e, portanto, deve ser proibida. Para se ter uma idéia do debate, ver Wertz e Fletcher (1992 e 1993). Outras técnicas permitem diagnosticar precocemente a má-formação, tais como a amniocentese ou biópsia de vilo corial, porém a ecografia é a mais popular delas. 
4 Apresentar uma estatística das mulheres que não desejam interromper a gestação em caso de má-formação incompatível com a vida é praticamente impossível no Brasil. Algumas mulheres, por questões religiosas, outras por motivações altruísticas para doar os órgãos do feto, e algumas poucas por resistir à infalibilidade do diagnóstico médico, decidem manter a gestação. Durante o trabalho de campo no serviço de referência no Distrito Federal, das 18 mulheres com diagnóstico de má-formação fetal incompatível com a vida extra-uterina, apenas uma não optou por razões religiosas. O bebê, com diagnóstico de encefalocele gigante, morreu uma hora após o nascimento. Além disso, há maior transparência desse processo entre as mulheres usuárias de serviços públicos de saúde, sendo estas as principais beneficiadas da parceria entre o sistema de saúde e o Ministério Público ou Judiciário.

5 A anencefalia corresponde à ausência dos hemisférios cerebrais, que foram substituídos por líquor. A anencefalia é vulgarmente conhecida por "ausência de cérebro" e é uma limitação incompatível com a vida, provocando a morte do recém-nascido imediatamente após o nascimento. Há alguns poucos relatos médicos de bebês com anencefalia que sobreviveram alguns meses, mas são raros. A anencefalia provoca desfiguração facial, pelo achatamento da parte frontal superior da cabeça, dada a ausência dos hemisférios e dos ossos do crânio. Recentemente, o Conselho Federal de Medicina editou parecer que autoriza a doação de órgãos de fetos anencefálicos, desde que autorizado pelos pais (CFM, 2003).

6 Desde a promulgação do Código Penal Brasileiro, em 1940, o tema do aborto vem sendo pauta legislativa constante no país. Somente na Câmara Federal foram 28 projetos de lei, o primeiro proposto em 1949 e o mais recente em maio de 2003 (Diniz, 2002). Para uma análise do debate legislativo nos anos 1990, sob uma perspectiva feminista, ver Baltar (1996). Os conceitos "aborto sentimental" e "aborto terapêutico" são os comumente utilizados pela literatura jurídica no Brasil.

7 Exemplo recente desse movimento foi a primeira audiência pública sobre interrupção seletiva da gestação promovida pelo Ministério Público Federal, em Porto Alegre, em abril de 2003. Nessa audiência, discutiram-se as implicações éticas do aborto seletivo em casos incompatíveis com a vida, renomeado para antecipação terapêutica de parto (ATP) (Diniz, 2003c). O Programa de ATP do Ministério Público do Distrito Federal e Territórios, Promotoria de Justiça Criminal de Defesa dos Usuários do Serviço de Saúde (Pró-Vida) é outro exemplo da força do Ministério Público nesse movimento. Até o momento foram autorizadas 93 interrupções seletivas, sendo o programa uma referência nacional (Costa, 2000). O aborto seletivo em casos de anomalias incompatíveis com a vida foi tentativamente incluído em uma das versões da proposta de revisão do Código Penal, porém não está mais em pauta.

8 Alguns programas públicos de interrupção seletiva da gestação, como é o caso do Instituto Fernandes Figueira, no Rio de Janeiro, solicitaram durante um período alvarás em casos de anomalias graves, porém compatíveis com a vida extra-uterina, tais como a síndrome de Down. Segundo Cristina Guilam, muito embora a equipe do programa estivesse certa de que o pedido seria negado, essa seria a única forma de provocar o debate ético sobre a moralidade do aborto seletivo na esfera judiciária. Todos os pedidos foram negados (Guilam, 2003).

9 Gollop (2003). Esse registro não corresponde ao total de abortos por má-formação fetal realizados no país, mas apenas àqueles para os quais houve solicitação judicial. Estima-se que número significativo de casos ocorra em clínicas e hospitais privados, sem qualquer recurso à justiça, havendo uma negociação entre pacientes e médicos, até mesmo para definir o que se entende por má-formação fetal, não se restringindo, portanto, aos casos de incompatibilidade do feto com a vida extra-uterina. Não há registros judiciais de alvarás ou processos autorizando interrupções em casos de síndrome de Down, por exemplo, muito embora muitos obstetras reconheçam sua moralidade e mesmo executem abortos nesses casos em clínicas 
privadas. Caso a prática tenha as proporções que estimo, haverá uma pauperização da síndrome de Down no Brasil em poucos anos.

10 Rio Verde de Mato Grosso (1991). Para uma análise dos primeiros alvarás brasileiros autorizando o aborto seletivo, ver Diniz (1997). Para uma discussão de alguns alvarás expedidos no Rio de Janeiro, ver Guilam (2003). Anelise Tessaro, sob uma perspectiva jurídica, analisa o conteúdo de cinco alvarás, proferidos entre os anos de 1992 e 1999 (Tessaro, 2002).

11 Todos os personagens do processo são homens, exceto Maria dos Santos e o feto.

12 O relatório médico que acompanha o processo registra essa informação - "relata ter feito uso de misoprostol no $2^{\circ}$ mês de gestação $(3$ comprimidos via oral e 3 comprimidos intravaginal)" - dado não percebido pelo promotor, porém registrado pelo juiz, muito embora não tenha utilizado esse dado para incriminá-la.

13 O primeiro indício da má-formação, na terceira ecografia, sugeria "feto prejudicado, pois há hidrocefalia". A hidrocefalia caracteriza-se por ser uma condição onde ocorre acúmulo excessivo de líquido cefalorraquiano em cavidades internas do cérebro. A quarta ecografia mostrou que o feto era, na verdade, anencefálico (Brasil, 1995, p. 12).

14 A decisão do promotor não foi ilegal, uma vez que se amparou na interpretação jurídica hegemônica e, mais do que isso, na interpretação literal do Código Penal. A intransigência justifica-se pelos fundamentos subjetivos elencados pelo promotor para fundamentar moralmente sua decisão.

15 Diniz (1997); Tessaro (2002); Guilam (2003). O argumento da tortura foi, até onde é possível ter confiabilidade nesse registro, inicialmente sugerido por um alvará proferido em Campinas, em 1994 (Brasil, 1994).

16 Sobre a estratégia de desumanização do feto nos processos de aborto seletivo, ver Diniz (1997). Alguns processos autorizando a interrupção em casos de anencefalia chegam a afirmar que o feto, por não ter cérebro, não deve ser considerado humano. Um exemplo de como essa interpretação extrapola o universo jurídico, vale conferir dois artigos de jornal de um padre católico, publicado no Jornal do Brasil (Altemeyer, 1996).

17 Um exemplo paradigmático dessa negociação da força do laudo médico de risco de vida à mulher é um processo ocorrido no Distrito Federal, em 2002. Ana Lima era uma gestante de um feto portador de encefalocele gigante, uma má-formação gravíssima e que, na maior parte dos casos, leva à morte precoce do feto. Em setembro de 2000, o Ministério Público do Distrito Federal e Territórios autorizou a interrupção da gestação de Ana Lima, com 31 semanas. Uma vez que a indução foi feita por parto normal e não se provocou a morte do feto, o bebê de Ana Lima nasceu e, com graves e limitantes deficiências, tendo falecido com dois anos e onze meses. O Conselho Regional de Medicina do Distrito Federal, em um ato de represália ao Ministério Público por fiscalização ao exercício da medicina, fez uma representação contra o promotor que autorizou a interrupção da gestação. O documento é um exemplo de como o laudo médico de risco à vida da mulher pode ser reinterpretado, pois assim o Conselho Regional de Medicina do Distrito Federal fundamentou a representação: “(...) [a recomendação da interrupção da gestação] baseava-se em duas condições, ambas falsas, a saber: 1) a interrupção da gravidez seria o 'único tratamento de saúde disponível para afastar o risco de morte da gestante' e 2) o feto seria inviável, por ser portador de acrania (...)". Ainda hoje esse é um caso de intensa discussão e utilizado por oponentes do aborto contra a autorização do aborto seletivo no Brasil (Brasil, 2002, p. 3). O caso de Ana Lima foi também noticiado pela mídia impressa (Tahan, 2003). 
18 Devo a Samantha Buglione a ressalva de que, muito embora o argumento da tortura tenha forte apelo humanista, o princípio da tortura nos direitos humanos sustenta-se na relação Estado, política e indivíduo e não na omissão de tratamento ou em áreas como a saúde (Buglione, 2003).

19 Em língua inglesa, o conceito é de disablism, até o momento sem traduções adequadas para a língua portuguesa. Os precursores do movimento social da deficiência foram: Fine e Asch (1988); Oliver (1990); Wendell (1996); Oliver e Barnes (1998); Thomas (1999); Francis e Silvers (2000). Em língua portuguesa, ver: Diniz (2003b).

20 As principais críticas ao argumento expressivista foram Kittay (2000); Nelson (2000); Press (2000) e Asch (2000)

\section{ABSTRACT}

Who authorizes selective abortion in Brazil? Physicians, Public Prosecutors, and Judges to the Fore

The Brazilian Penal Code does not explicitly define the issue of abortion based on fetal anomaly. It is estimated that some two thousand abortions have been authorized to date in Brazil on the basis of fetal malformations. The 1990s were decisive for this process of recognition of the right to selective abortion, even though there is still intense court controversy over its legality. The article analyzes the arguments used by physicians, lawyers, public prosecutors, and judges to justify the morality of the first request for selective abortion in the Federal District in 1995.

Keywords: Selective abortion; abortion due to fetal malformation; feminist bioethics.

Recebido em: 29/09/2003

Aprovado em: 13/10/2003. 